Scientific Electronic Archives

Issue ID: Sci. Elec. Arch. Vol. 14 (10)

October 2021

DOI: http://dx.doi.org/10.36560/141020211480

Article link: https://sea.ufr.edu.br/SEA/article/view/1480

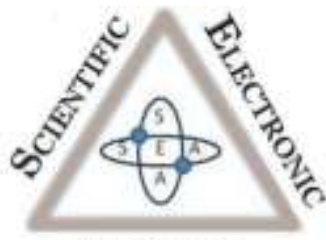

ArChives

\title{
Gestational losses after innovating with two embryos in a fixed-time embryo transfer program
}

\author{
Carla Neves Barbosa \\ Universidade Federal de Rondonópolis \\ Itamar Martins da Silva \\ Universidade Federal de Rondonópolis \\ Felipe De Col \\ De Col Reprodução Bovina
}

Juan Carlos Domínguez Fernández de Tejerina

Universidad de León, Campus Vegazana

Corresponding author

Rodolfo Cassimiro de Araujo Berber

Universidade Federal de Rondonópolis

rodolfo.berber@ufr.edu.br

\begin{abstract}
The aim of this study was to quantify the pregnancy rate after implantation of two embryos after FTET protocols, as well as to monitor pregnancy losses until parturition, evaluating, mainly, if this strategy results in more number of animals born. Therefore, 423 multiparous recipients were selected, standardized in terms of body score, who had high-quality corpora lutea. Animals were randomly divided into two groups according to one or two embryos transferred ( 1 embryo $=$ Control, $n=237 ; 2$ embryos $=$ Group $1, n=186)$. All recipients received the same hormonal treatment, which consisted of administering, on Day $0,2 \mathrm{~mL}$ of estradiol benzoate (Gonadiol, ZOETIS) $+1.9 \mathrm{~g}$ multidose 1st use progesterone implant (CIDR, ZOETIS); on Day 8 the implants were removed + injected $0.4 \mathrm{~mL}$ of estradiol cypionate (E.C.P, ZOETIS) + $1.5 \mathrm{~mL}$ of eCG (Novormon, ZOETIS) $+1 \mathrm{~mL}$ of dinoprost tromethamine (Lutalyse, ZOETIS). The animals were evaluated by ultrasonography at 30 and 60 days after embryo transfer, to diagnose the success rate and embryo losses during this period. Furthermore, information was collected on births, length of gestation, number of twin births, number of childbirth assistance and the weight of the calves. The results showed that Group 1 had better success than the Control, with higher conception rates at 30 days $(68.3 \%$ vs. $53.2 \%, P<0.001)$ and at 60 days (62.9\% vs. $52.3 \% ; P<0$.05). The number of animals born was also higher for Group 1 (53.3\% vs. $43.3 \%, P<0.01)$. The percentage of twins born in Group 1 was $17.9 \%$, and the animals had lower weight compared to the Control $(34.29 \pm$ 7.36 vs $37.63 \pm 5.73, P<0.05)$. The length of pregnancy and the number of assistances were similar between groups. In conclusion, the strategy adopted in this experiment suggests a considerable increase in the calf birth rate, but losses during pregnancy and their mechanisms need to be elucidated.
\end{abstract}

Keywords: FTET, gestational losses, embryo transfer, bovine

\section{Introduction}

The search for improvement in reproductive efficiency is an effective tool for the economic maintenance of economic development in beef cattle. Diversification in the use of fixed-time insemination (TAI) and fixed-time transfer (FTET) protocols has been common since the early 2000s, as it increases the number of animals inseminated and facilitates large-scale embryo innovation (Bo et al. 2004; Aguiar et al., 2019; Pinto Neto et al., 2018; Baruselli et al., 2004).

Another alternative to increase profit is the dissemination of the genetics of superior animals through biotechniques with the production of donor embryos, either in vivo or in vitro, in order to increase the number of products (Hansen 2020; Mebratu et al. 2020; Bo et al., 2019). Selection of superior genetic or phenotypic animals has been the 
basis of the donor selection since ET`s inception (Philips and Jahike, 2016). Genetic superiority animals that contribute to the genetic objectives of the scheme and likelihood of producing large numbers of usable embryos are the two broad criteria for selecting donor cows for most embryo transfer scheme (Thibier, 2006)

To maximize embryo survival in the recipient female following transfer, conditions in the recipient reproductive tract should closely resemble those in the donor. This requires synchronization of the estrous cycles between the donor and the recipients, optimally within one day of each other. Synchronization of the recipients can be done in a similar manner and at the same working time as the donor cows (Galina \& Orihuela, 2007).

By another hand, loss of pregnancy can occur at many different stages of gestation and for a variety of causes (Wiltbank et al., 2016; Sakatani, 2017; Farin et al., 2001; Rizos et al., 2002). Ealy et al. (2019) reported that pregnancy losses were observed throughout gestation, but losses were most prevalent early in gestation. Approximately $40 \%$ of cows receiving an IVP embryo at day $7 / 8$ post-estrus were no longer pregnant at day 18 to 21 of gestation, as determined by the absence of a conceptus in excised uteri or poor quality of corpus luteum fuction. By day 30 to 40 of gestation, being $60 \%$ of the recipients were not pregnant. Further pregnancy losses were observed thereafter, albeit at a lower rate, with around $5 \%$ of pregnancies lost at day 45 and 90 and another $7 \%$ loss thereafter. Only $27.1 \%$ of cattle receiving IVP embryos maintained the pregnancy to term.

It is noticeable that the endocrine and biochemical relationships between the embryo and the maternal uterus during the critical period are far from being fully elucidated (Leese, 2012), since postpartum success depends on several variables related to the embryo (quality, stage of development, damage or injuries caused to the embryo, production method, storage and fertilization); to the uterus (hormones, vascularization and tissue changes); and to the ovaries (quality, mass and hormonal production of the corpus luteum). Due to the difficulty of isolating the variables, we hypothesized that it would be possible to increase the conception rate using the strategy of only doubling the number of implanted embryos, resulting in greater signaling of products synthesized by the embryo related to maternal recognition, as well as increasing the chance of maintenance of the corpus luteum more effectively, even without isolating these variables related to maternal recognition during the critical period. Thus, the aim of this study was to quantify the pregnancy rate after implantation of two embryos after FTET protocols, as well as to monitor pregnancy losses until parturition, evaluating, mainly, if this strategy results in more number of animals born.

\section{Materials and Methods}

Screening of animals and standardization of variables

Seeking to minimize the possible variables that could interfere with conception rates, the same management conditions and animal conditions were standardized before constituting the two treatment groups. Thus, the experiment was carried out on the same property, located in Carlinda, Mato Grosso, Brazil (Latitude 09 57' 29" S, Longitude: 55 49' 56" W). All animals were kept under ad libitum grazing, with the same offer of mineral supplementation and access to water. Furthermore, the animals presented the same body condition at the time of inoculation (score of 3 , scale of $1-5$ ) and health status. All donors were of the Nellore breed and were inseminated with sexed semen to males from the same Aberdeen bull. Fresh embryos produced were transferred in an expanded bastocyte stage, with quality rating 2 or 3 (STRINGFELLOW, 1998), to multiparous Nellore recipients, previously examined by ultrasound to assess the corpus luteum according to the criteria reported by Leal (2009), and classified as good/excellent.

Of the total of 423 recipients considered good/excellent, 237 were receive one embryo (Control) and 186 received two embryos (Group 1). To improve randomization, it was decided to allocate the recipients alternately, as they were being implanted with one or two embryos.

All recipients received a FTET protocol that consisted of administering, on Day $0,2 \mathrm{~mL}$ of estradiol benzoate (Gonadiol, ZOETIS) $+1.9 \mathrm{~g}$ multidose 1st use progesterone implant (CIDR, ZOETIS); on Day 8 the implants were removed + injected $0.4 \mathrm{~mL}$ of estradiol cypionate (E.C.P, ZOETIS) $+1.5 \mathrm{~mL}$ of eCG (Novormon, ZOETIS) +1 $\mathrm{mL}$ of dinoprost tromethamine (Lutalyse, ZOETIS).

Twenty-four hours after implant removal from the recipients, follicular aspiration was performed in the laboratory. Follicular aspiration was performed from selected cows' ovaries from the slaughterhouse. These ovaries were collected and transported in saline solution (room temperature) inside thermos bottles. The time between the collection of ovaries in the refrigerator and the follicular aspiration procedure in the laboratory was 4 hours.

In the laboratory, the ovaries were washed and placed in saline solution heated in a water bath at $37^{\circ} \mathrm{C}$. In sequence, the follicles were aspirated with a needle (20G) and syringe (10 mL). The follicular fluid from the syringe was placed in a $50 \mathrm{ml}$ tube, also kept at a temperature of $37^{\circ} \mathrm{C}$. After the decantation process, the supernatant was removed with a $5 \mathrm{~mL}$ pipette and the pellet washed twice with approximately $20 \mathrm{~mL}$ of saline solution (heated to $37^{\circ} \mathrm{C}$ ). The supernatant was removed again, and the pellet was resuspended in $20 \mathrm{~mL}$ of saline solution and placed in a petri dish (100 $\mu \mathrm{l})$. Next, visualization and selection of all viable oocyte cumulus complexes was performed. Selected oocytes were transferred in a Petri dish with saline solution $(35 \mu \mathrm{l})$. 
After screening, these structures were washed in TCM 199 maturation medium added with $10 \%$ fetal bovine serum, to be placed in the falcon's $5 \mathrm{ml}$ tubes for maturation. In each tube, 30 oocytes were placed, composed of maturation medium (400 microliters) and mineral oil (200 microliters). Afterwards, the tubes were incubated for 22 hours. Oocytes were washed in IVF medium and transferred to IVF plate. The semen dose was thawed and placed in a gradient column formed by $40 \%$ and $80 \%$ PureSperm, and centrifuged for 5 minutes at $5000 \mathrm{rpm}$. The supernatant was removed and the pellet resuspended in $1 \mathrm{~mL}$ of IVF medium, returning for the 2nd centrifugation at $3000 \mathrm{rpm}$ for 3 minutes. After centrifugation, the supernatant was removed, leaving a 100 microliter pellet for fertilization. Fertilization was performed by adding 10 microliters of the resuspended semen to each drop (50 microlites of medium) which had 30 mature oocytes. After fertilization, incubation was carried out for 22 hours.

Afterwards, the zygotes were removed from the fertilization plate for washing, with in vitro culture medium (IVC), and mechanical denudation. After washing, the zygotes are placed in CIV plates (drop of 60 microliters), which were incubated in an atmosphere of $5.5 \% \mathrm{CO} 2$ and $5.5 \% \mathrm{O} 2$ for 7 days. On the third day (48 to 72 hours after fertilization) non-fertilized or degenerated structures were removed, replacing approximately $50 \%$ of the drop volume, and on the sixth day, the procedure was repeated. The classification of blastocysts was carried out on the seventh day and the selected ones were prepared and filled in 0.25 straws containing Hsof medium.

The embryos started to be bottled about 1 hour before leaving for the field, and it took 30 minutes to reach the property. The hormonal protocol of the recipients was carried out at a predetermined time, starting at 7:00 am, just like the transfer of embryos.

On the day of embryo transfer, the recipients' ovaries were examined by ultrasonography to diagnose the quality of the corpus luteum (classified as $1,2,3$ or cavitary). Having confirmed the quality of the corpus luteum, the embryos were transferred to the uterine horn ipsilateral to ovulation.

\section{Variables analyzed and statistical design}

To monitor the success rate of the strategy, quantification and characterization of the moment of pregnancy losses, ultrasound examinations were performed on days 30,60 after embryo implantation, as well as the real date of parturition, the number of twin births, the duration of pregnancy (average \pm standard deviation), if there was assistance in the birth and the weight of the calf at birth (average \pm standard deviation) were recorded for analysis. Every numerical difference between the moments of evaluation was considered as pregnancy loss.

Before performing the comparison of results between treatments, the normality was verified using Kolmogonov-Smirnov test. Conception rates on Day 30 and Day 60, losses between these assessments, number of calves born, number of twins born, losses throughout pregnancy were calculated as a percentage. Pregnancy length and calf birth weight were expressed as mean and standard deviation. All variables evaluated were analyzed by ANOVA and compared by T-student test, considering a significance level of $P<0.05$.

\section{Results and discussion}

The results obtained during the pregnancy of the recipients suggested that the hypothesized strategy was successful, but with a higher volume of pregnancy losses for Group 1. Even accounting for pregnancy losses, Group 1 had better final performance than the Control, as shown in Table 1.

The highest conception rate at 30 days in Group 1 (Table 1) demonstrated that the twoembryo implantation strategy resulted in better performance during the critical period, suggesting that two embryos may have generated better maternal recognition or a better effect in blocking luteolysis after embryo implantation. Pugliesi et al. (2014) reported that a successful pregnancy is established and maintained in cattle, the corpus luteum $(\mathrm{CL})$ must remain functional beyond the time when luteolysis would normally occur. Interferon-T (IFN-T), a glycoprotein secreted by the conceptus, inhibits the pulsatile secretion of prostaglandin $\mathrm{F} 2 \alpha$ (PGF2 $\alpha$ ) from the endometrium that causes luteolysis. Consequently, CL survives and secretes progesterone (P4), leading to the onset of pregnancy (Spencer et al., 2006)

Table 1 - Comparison between implantation with one or two embryos in FTET protocols

\begin{tabular}{lccc}
\hline Variables & Control (1 embryo) & Group 1 (2 embyos) & $\mathrm{P}$ \\
\hline Number of recipient $(\mathrm{n})$ & 237 & 186 & \\
Conception rate at 30 days (\%) & 53.2 & 68.3 & 0.001 \\
Conception rate at 60 days (\%) & 52.3 & 62.9 & 0.028 \\
Number of calves born (\%) & 43.3 & 53.3 & 0.003 \\
Number of twins (\%) & 0.0 & 17.9 & $<0.001$ \\
Calf weight (average \pm SD) & $37.63 \pm 5.73$ & $34.29 \pm 7.36$ & 0.007 \\
Gestation length (average \pm SD) & $283.8 \pm 3.90$ & $285.5 \pm 7.80$ & 1.056 \\
\hline
\end{tabular}

On the other hand, the conception rate of Group 1 at Day 60 indicated greater gestational loss than Control between days 30 and $60(5.4 \%$ vs.
$0.9 \%$, respectively; $\mathrm{P}<0.01$ ), which apparently has no relationship with luteolysis involved in the critical period, not with maternal recognition, but with 
failures in the placentation process. The mechanisms related to the growth and early development of extraembryonic membranes are still not fully elucidated. It is known that modifications in the chorion (Costa et al., 2020), in the allantois (Thompson et al., 2000) and in the yolk sac (De Sousa et al., 2001) resulted in pregnancy losses. Also, despite not having been the focus of this experiment, it is possible to consider that the losses may have been caused by situations related to the development of cotyledons (Assis Neto et al., 2009), or by changes at the cellular and/or matrix level extracellular, mainly of structures called glycosaminoglycans and proteoglycans, which are responsible for ensuring hydration, tissue elasticity and have a fundamental role in vascular growth that accompanies the development of the placenta (Reynolds et al., 2001).

The main purpose of this experiment was to evaluate the number of calves born, even knowing that there would be losses during pregnancy that would not be fully elucidated. In fact, the largest number of calves born was from Group 1 (Table 1), which suggests that the strategy of implanting two embryos can be interesting in terms of the final result in the productivity of calves. Although gestational losses were greater for animals that received two embryos (15\% vs. $9.9 \%, \mathrm{P}<0.05)$, the high initial conception rates and the percentage of twin births ensured the highest number of calves born (Table 1) at the end of pregnancy. It is noteworthy that despite the contribution of twin births in the present experiment, the rate found $(17.9 \%)$ was half that reported by Cavalieri et al. (2018).

The duration of pregnancy was similar between the two groups in the present experiment, differing from the findings of Cavalieri et al.(2018), who observed a shorter gestational period in protocols for obtaining twins, associating FTAI with subsequent embryo implantationln fact, it is common for twin pregnancies to be shorter in mammals, as there is an earlier induction of fetal cortisol release, generating a cascade of events that result in placental ripening, hormonal releases, uterine contractions for expelling the offspring (Echternkamp et al., 2007a, Echternkamp et al., 2007b).

It is common to increase the number of dystocia in twin births (Knight et al., 2001; Cavalieri et al., 2018). In the present experiment, the loss due to malformation of 4 calves of two twin pregnancies was observed. Still, there was only one assistance in the birth of one of the animals in Group 1, which represented, in the authors' understanding, a very low rate of assistance. In general, difficulties in childbirth or dystocia may be the result of failures in adrenal signaling or even fetal size, determined by race, prolonged gestation or changes in fetal static. In this sense, the crossing of an Aberdeen bull and a Nelore female apparently may have influenced our results, including the average birth weight of the calves. The weight of the calves in Group 1 was lower than in the Control (Table 1), corroborating the findings of Echternkamp et al. (2007a); however, the average calf weights at birth in the present experiment may explain the lower rate of assistance during birth and similarity in the gestational period, as the weights rarely exceeded $40 \mathrm{~kg}$. It is noteworthy that the reduction in the individual size of each fetus is a consequence of competition for space and availability of nutrients (Aguiar et al., 2019).

\section{Conclusions}

Under the conditions of the present experiment, it can be concluded that the strategy of implanting two embryos presents an alternative to improve the number of born calves.

As for pregnancy losses, the available literature is not yet able to elucidate all the events that negatively influence the final outcome of pregnancy, but it was noticeable, from the results of this experiment, that twin pregnancies had greater losses after 30 days of conception, the which suggests that the gestational losses were due to the gestational processes related to this period.

\section{References}

Aguiar, T. S., Moreira, P. S. A., Moreti, B. S., Berber, G. C. M., Pinto-Neto, A., \& Berber, R. C. A. (2019). Strategy to improve the parturition ability in crossbred recipients implanted with embryos produced in vitro. Scientific Electronic Archives, 12(1), 81-84. https://doi.org/10.36560/1212019682

Alan D Ealy, Lydia K Wooldridge, Sarah R McCoski, BOARD INVITED REVIEW: Post-transfer consequences of in vitro-produced embryos in cattle, Journal of Animal Science, Volume 97, Issue 6, June 2019, Pages 25552568, https://doi.org/10.1093/jas/skz116

Antônio C. de Assis Neto, José Antônio B. Morceli, Ricardo da Fonseca, Carlos Eduardo Ambrósio, Flávia T.V. Pereira e Maria Angélica Miglino. Evolução morfométrica dos anexos embrionários e fetais bovinos obtidos por monta natural, com 10 a 70 dias da gestação. Pesq. Vet. Bras. 29(10):859862, outubro 2009. https://doi.org/10.1590/S0100$\underline{736 \times 2009001000014}$

Bó G.A., Moreno D., Cutaia L., Baruselli P.S. \& Reis, E.L. 2004. Manipulação hormonal do ciclo estral em doadoras e receptoras de embrião bovino. Acta Scientiae Veterinariae, 32 (Supl ): p.1-22

Bo, Gabriel A.; Cedeno, Andrés and Mapletoft, Reuben J.. Strategies to increment in vivo and in vitro embryo production and transfer in cattle. Anim. Reprod. [online]. 2019, vol.16, n.3 [cited 2021-0507], pp.411-422. https://doi.org/10.21451/19843143-ar2019-0042. 
Cavalieri, F. S. R. et al. Estudo sobre indução de partos gemelares em vacas nelore. Archives of Veterinary Science, [S.I.], v. 23, n. 4, dec. 2018. ISSN 2317-6822.

doi:http://dx.doi.org/10.5380/avs.v23i4.51910.

Clara Slade Oliveira, Viviane Luzia da Silva Feuchard, Celio de Freitas, Paola Maria da Silva Rosa, Agostinho Jorge dos Reis Camargo, Naiara Zoccal Saraiva, In-straw warming protocol improves survival of vitrified embryos and allows direct transfer in cattle, Cryobiology, Volume 97, 2020, https://doi.org/10.1016/j.cryobiol.2020.02.007

David A. Roper, F. Neal Schrick, J. Lannett Edwards, Fred M. Hopkins, Tulio M. Prado, John B. Wilkerson, Arnold M. Saxton, Charles D. Young, W. Brandon Smith. Factors in cattle affecting embryo transfer pregnancies in recipient animals, Animal Reproduction Science, Volume 199, 2018, https://doi.org/10.1016/j.anireprosci.2018.11.001

De Sousa PA, King T, Harkness L, Young LE, Walker SK, Wilmut I. Evaluation of gestational deficiencies in cloned sheep fetuses and placentae. Biol Reprod. 2001 Jul;65(1):23-30. doi: 10.1095/biolreprod65.1.23. PMID: 11420219.

Farin, P. W., A. E. Crosier, and C. E. Farin. 2001. Influence of in vitro systems on embryo survival and fetal development in cattle. Theriogenology 55:151170. doi: S0093-691X(00)00452-0

Galina, C. \& Orihuela, A. (2007). The detection of estrus in cattle raised under tropical conditions: What We know and What We Need To Know Hormones and Behavior, 52, 32-38.

Guilherme Pugliesi, Bruna T. Miagawa, Yasmin N. Paiva, Moana R. França, Luciano A. Silva, Mario Binelli, Conceptus-Induced Changes in the Gene Expression of Blood Immune Cells and the Ultrasound-Accessed Luteal Function in Beef Cattle: How Early Can We Detect Pregnancy?, Biology of Reproduction, Volume 91, Issue 4, 1 October 2014, 95,

12, https://doi.org/10.1095/biolreprod.114.121525

H.S. Costa, F.V. Câmara, F.V.F. Bezerra, et al. 2020. Desenvolvimento embrionário/fetal, placentação e glicosaminoglicanos no aparelho reprodutor feminino e na placenta. Acta Scientiae Veterinariae. 48: 1728. DOI: 10.22456/16799216.100339

Hansen, Peter J. The incompletely fulfilled promise of embryo transfer in cattle-why aren't pregnancy rates greater and what can we do about it?, Journal of Animal Science, Volume 98, Issue 11, November 2020, skaa288, https://doi.org/10.1093/jas/skaa288

Leal, L. da S., Oba, E., Fernandes, C. A. de C., \& Sá Filho, O. G. de. (2009). Avaliação do corpo lúteo, contratilidade uterina e concentrações plasmáticas de progesterona e estradiol em receptoras de embriões bovinos. Ciência Animal Brasileira, 10(1), 174-183. Recuperado de https://revistas.ufg.br/vet/article/view/448

Leese, H. J. (2012). Metabolism of the preimplantation embryo: 40 years on, Reproduction, 143(4), 417-427. Retrieved Jun 7, 2021, from https://rep.bioscientifica.com/view/journals/rep/143/ $\underline{4 / 417 . x m l}$

Mebratu, B., Fesseha, H., \& Eyob Goa, E. (2020). Embryo Transfer in Cattle Production and Its Principle and Applications, Int. J. Phar. \& Biomedi. Rese. 7(1), 40-54. doi: http://dx.doi.org/10.18782/2394-3726.1083

Miki SAKATANI, Effects of heat stress on bovine preimplantation embryos produced in vitro, Journal of Reproduction and Development, 2017-045, $2017 / 05 / 12$, Online ISSN 1348-4400, Print ISSN 0916-8818, https://doi.org/10.1262//rd.2017-045

Milo C. Wiltbank, Giovanni M. Baez, Alvaro GarciaGuerra, Mateus Z. Toledo, Pedro L.J. Monteiro, Leonardo F. Melo, Julian C. Ochoa, José E.P. Santos, Roberto Sartori, Pivotal periods for pregnancy loss during the first trimester of gestation in lactating dairy cows, Theriogenology, Volume 86, Issue 2016, https://doi.org/10.1016/..theriogenology.2016.04.037

P. S. Baruselli, E. L. Reis, M. O. Marques, L. F. Nasser, G. A. Bó. The use of hormonal treatments to improve reproductive performance of anestrous beef cattle in tropical climates. Animal Reproduction Science 82-83 (2004) 479-486. https://doi.org/10.1016/. anireprosci.2004.04.025

Philips, P. \& Jahinke, M. (2016). Embryo transfer (Technique, Donors, and Recipients). Articles in Veterinary Clinics of North America Food animal practice. Pp. 366-384.

PINTO NETO, Adalgiza et al. Productive and Reproductive Perfomance of Dairy Cows During Peripartum. Braz. arch. biol. technol. [online]. 2018, vol.61 [cited 2021-05-07], e18160278. Available from:

$<$ http://www.scielo.br/scielo.php?script=sci_arttext\& pid $=S 1516$

$89132018000100317 \&$ Ing=en\&nrm=iso $>$.

Epub Nov 14, $2018 . \quad$ ISSN

4324. https://doi.org/10.1590/1678-4324-

$\underline{2018160278}$

Reynolds LP, Redmer DA. Angiogenesis in the placenta. Biol Reprod. 2001 Apr;64(4):1033-40. doi: 10.1095/biolreprod64.4.1033. PMID: 11259247.

Rizos, D., $\quad$ F. Ward, P. Duffy, M. $\quad$ P. Boland, and $P$. Lonergan. 2002. Consequences of bovine 
oocyte maturation, fertilization or early embryo development in vitro versus in vivo: implications for blastocyst yield and blastocyst quality. Mol. Reprod. Dev. 61:234-248. doi:10.1002/mrd.1153

S. E. Echternkamp, R. A. Cushman, M. F. Allan, R. M. Thallman, K. E. Gregory, Effects of ovulation rate and fetal number on fertility in twin-producing cattle,, Journal of Animal Science, Volume 85, Issue 12, December 2007, Pages 3228-3238, https://doi.org/10.2527/jas.2007-0209

S. E. Echternkamp, R. M. Thallman, R. A. Cushman, M. F. Allan, K. E. Gregory, Increased calf production in cattle selected for twin ovulations,, Journal of Animal Science, Volume 85, Issue 12, December 2007, Pages 32393248, https://doi.org/10.2527/jas.2007-0210

Spencer Thomas E., Johnson Greg A., Bazer Fuller W., Burghardt Robert C., Palmarini Massimo (2006) Pregnancy recognition and conceptus implantation in domestic ruminants: roles of progesterone, interferons and endogenous retroviruses. Reproduction, Fertility and Development 19, 65-78. https://doi.org/10.1071/RD06102

Stringfellow, D.A.; Seidel, S.M. Manual da Sociedade Internacional de Transferência de Embriões. IETS, p. 112-113, Illinois, 1998

Thibier, M. (2006). Data retrieval committee annual report. Embryo Transfer Newsletter, 24(4), 12-18.

Thompson J.G. \& Peterson A.J. 2000. Bovine embryo culture in vitro: new developments and posttransfer consequences. Human Reproduction. 15(5 Suppl): 59-67 